\title{
The Effects of Neuroleptics on Facial Action in Schizophrenic Patients
}

\author{
F. Schneider ${ }^{1 / 4}$, H. Ellgring ${ }^{2}$, J. Friedrich ${ }^{1}$, I. Fus ${ }^{1}$, T. Beyer ${ }^{3}$, H. Heimann ${ }^{1}$, W. Himer ${ }^{1}$ \\ ${ }^{1}$ Department of Psychiatry, University of Tübingen, Germany \\ ${ }^{2}$ Institute of Psychology, University of Würzburg, Germany \\ ${ }^{3}$ Institute of Psychology, Free University of Berlin, Germany \\ ${ }^{4}$ Department of Psychiatry, University of Pennsylvania, USA
}

\section{Summary}

This paper describes the influence of neuroleptic therapy on facial action in drug-naive schizophrenics. In a comparative study of medicated and unmedicated schizophrenic patients, the coordinates of 12 small light-reflecting points, attached to subjects' faces, were computer-recorded and analyzed automatically during a semistandardized clinical interview. In addition, facial activity in videotaped interviews was coded using the Facial Action Coding System (FACS). Each sample group comprised of eight patients with the DSMIII-R diagnostic criteria "schizophrenia" or "schizophreniform disorder". Subjects were studied on two occasions, one shortly after admission to the hospital, the other three weeks later. Group 1 was unmedicated during the first session, whereas group 2 was medicated throughout the study. Three weeks after the start of medication, at the second interview, both recording methods showed a reduction in facial activity and facial expression across all subjects in group 1. The facial action of patients in group 2 , however, remained unchanged.

\section{Der Einfluß von Neuroleptika auf die Mimik schizophrener Patienten}

Ziel der vorliegenden Arbeit war die Untersuchung des Einflusses von Neuroleptika auf die Mimik von unmedizierten schizophrenen Patienten. Während eines halbstandardisierten klinischen Interviews wurde die Beweglichkeit von zwölf kleinen, licht-reflektierenden Punkten, die in das Gesicht von medizierten und unmedizierten schizophrenen Patienten geklebt wurden, automatisch im Zeitverlauf gemessen. Ergänzend wurde der mimische Ausdruck mit dem Facial Action Coding System (FACS) kodiert, wofür die Patienten gleichzeitig mit Video aufgenommen wurden. Jede der beiden Gruppen bestand aus acht Patienten mit den DSM-IIIR-Diagnosen „Schizophrenie“ oder „Schizophrenieforme Störung“". Die Patienten wurden einmal direkt nach der stationären Aufnahme und ein zweites Mal nach drei Wochen untersucht. Die Patienten der ersten Gruppe waren zum ersten Zeitpunkt nicht mit Neuroleptika mediziert, während die der zweiten Gruppe schon zu diesem Zeitpunkt entsprechende Medikamente einnahmen. Es konnte eine Reduktion der mimischen Beweglichkeit des gesamten Gesichtes im Sinne einer neuroleptisch bedingten Hypomimie der primär Neuroleptika-unbehandelten Patienten bei der zweiten Untersuchung beobachtet werden. Die andere Gruppe Schizophrener, die zu beiden Zeitpunkten mit Neuroleptika behandelt waren, zeigte keine Veränderung in ihrer mimischen Beweglichkeit.

\section{Introduction}

Unusual facial expressivity in schizophrenic patients is a well-established phenomenon. Facial expressions of schizophrenics are frequently described as bizarre, emotionless, rejecting, and uncoordinated in the literature because they display a lack of holistic configurations during the general pace of expression (Esquirol, 1838; Morison, 1853). These features had been mentioned long before the discovery of neuroleptics (Bleuler, 1911, Kraepelin, 1883) and have been repeatedly emphasized in the past by psychiatrists (Marsden et al., 1975;
Owens et al., 1982; Rogers and Hymas, 1988). Moreover, the facial expressivity of schizophrenic patients seems to elicit a "praecox-feeling" in the diagnostician. To date, researchers have been unable to operationalize this diagnostic inclination in terms of facial expressivity due to the unavailability of appropriate instruments for assessment.

Only within the last few years have experimental studies of the facial expressions of schizophrenic patients employing valid designs and data analyses (e.g., Krause et al., 1989; Martin et al., 1990; Pitman et al., 1987; Schneider et al., 
1992; Steimer-Krause et al., 1990). In one of our previous studies (Schneider et al., 1990) we were able to specify some characteristics of facial expressivity across time in schizophrenic patients with a computer-based analysis of facial action (at that time the analysis was limited to four facial points). The sum of these features was described as disintegrative facial action (cf. Heimann and Spoerri, 1957): a reduction of facial action in the upper facial region during a social interaction condition, facial action indifference in response to disparate emotional and situational stimuli, as well as the inability of the observers to rate the intensity of expressed facial action as objectively as the computer analysis on an intensity rating scale. Furthermore, it remained unclear to what extent these experimentally induced effects in schizophrenics are of nosological significance, since a reduction of facial action in the upper region of the face was also found in depressives. An unsolved question is whether this effect may possibly be an indicator of severity of illness. Another plausible assumption may be that the conspicuous facial actions found in schizophrenics are simply extrapyramidal side-effects of neuroleptic medication expressed as reduced facial activity. Moreover, it is known that neuroleptics affect those cortical and subcortical structures which regulate upper facial activity (Rinn, 1984).

The objective of this study was to describe changes in facial movements in schizophrenics over the course of therapy, in order to analyze the effects of neuroleptics (by quantitatively assessing a reduction of facial actions caused by neuroleptics) and the effects of improved clinical status on the patients' facial actions. We used two different types of analyses. The first analysis was quantitative in that facial activity was assessed by a rater-independent automatic analysis, while the other assessment was a qualitative behavior analysis which involved the systematic observation of facial behavior by means of the Facial Action Coding System (FACS) (Ekman and Friesen, 1978) and its coding in terms of individual action units.

\section{Method}

\section{Patients}

Two groups of eight schizophrenic or schizophreniform patients participated in this study (DSM-III-R-Criteria; diagnosed by a German version of the Structural Clinical Interview according to DSM-III-R [SCID]) (Wittchen et al., 1987). Table 1 contains demographic and clinical data of the two groups. Table 2 lists the medications and their side-effects.

In contrast to patients in group2, patients in group 1 were unmedicated at the first session. Six of these patients had never been on any neuroleptics before, while the other two had stopped using neuroleptics 13/50weeks prior to study onset.

Patients in group 1 were given neuroleptics immediately following the first session $\left(\mathrm{T}_{1}\right)$. Neuroleptics and dosage were based on the clinical state of the patients. Group 2 simply continued taking the medication. The second recording $\left(\mathrm{T}_{2}\right)$ was done approximately 22 days later.

The following expert rating scales were used after each of the two sessions: Global Assessment Scale (GAS) (Endicott et al., 1976), Brief Psychiatric Rating Scale (BPRS)
Tab. 1 Demographic und clinical data. The improvements in clinical state from $T_{1}$ to $T_{2}$ ( 3 weeks) were significant on all scales in both groups, see text.

\begin{tabular}{|c|c|c|c|}
\hline Variable & $\begin{array}{l}\text { Group } 1 \\
\text { (unmedicated) }\end{array}$ & $\begin{array}{l}\text { Group } 2 \\
\text { (medicated) }\end{array}$ & $\begin{array}{l}\text { t-test } \\
t / p \\
(d f=14)\end{array}$ \\
\hline Gender & $6 m / 2 f$ & $5 m / 3 f$ & \\
\hline Age & $26.1 \mathrm{y} . / \mathrm{SD}=5.2$ & 26.1 y. $/ S D=11.5$ & $0.62 / \mathrm{ns}$ \\
\hline \multicolumn{4}{|l|}{$\begin{array}{l}\text { Diagnosis } \\
\text { (DSM II-R) }\end{array}$} \\
\hline 295.1 & 2 & 0 & \\
\hline 295.3 & 1 & 1 & \\
\hline 295.4 & 1 & 2 & \\
\hline 295.9 & 4 & 5 & \\
\hline \multicolumn{4}{|l|}{ First } \\
\hline occurrence & 3 yes $/ 5$ no & 3 yes $/ 5$ no & \\
\hline $\begin{array}{l}\text { Duration } \\
\text { of current }\end{array}$ & & & \\
\hline episode & $24.0 \mathrm{w} / \mathrm{SD}=34.4$ & $8.6 \mathrm{w} / \mathrm{SD}=8.0$ & $-1.22 / \mathrm{ns}$ \\
\hline \multicolumn{4}{|l|}{ GAS } \\
\hline $\begin{array}{l}\mathrm{T}_{1} \\
\mathrm{~T}_{2}\end{array}$ & $\begin{array}{l}M=29.4 / S D=9.0 \\
M=41.3 / S D=12.8\end{array}$ & $\begin{array}{l}M=36.0 / S D=8.0 \\
M=48.5 / S D=7.6\end{array}$ & $\begin{array}{r}-1.53 / \mathrm{ns} \\
1.34 / \mathrm{ns}\end{array}$ \\
\hline \multicolumn{4}{|l|}{ BPRS } \\
\hline $\begin{array}{l}\mathrm{T}_{1} \\
\mathrm{~T}_{2}\end{array}$ & $\begin{array}{l}M=58.8 / S D=14.8 \\
M=44.1 / S D=10.5\end{array}$ & $\begin{array}{l}M=60.1 / S D=13.6 \\
M=36.5 / S D=8.3\end{array}$ & $\begin{array}{r}0.19 / \mathrm{ns} \\
-1.61 / \mathrm{ns}\end{array}$ \\
\hline \multicolumn{4}{|l|}{ SANS (SS) } \\
\hline $\mathrm{T}_{1}$ & $M=16.6 / S D=4.7$ & $M=16.0 / S D=3.2$ & $-0.31 / \mathrm{ns}$ \\
\hline
\end{tabular}

Tab. 2 Medication and sideeffects (n: number of patients)

\begin{tabular}{|c|c|c|c|}
\hline Variable & $\begin{array}{l}\text { Group } 1 \\
\text { (unmedicated) }\end{array}$ & $\begin{array}{l}\text { Group } 2 \\
\text { (medicated) }\end{array}$ & $\begin{array}{l}\text { t-test } \\
t / p(d f=16)\end{array}$ \\
\hline \multicolumn{4}{|l|}{ Neuroleptics } \\
\hline$T_{1}(n)$ & 0 & 8 & \\
\hline$T_{2}(n)$ & 8 & 8 & \\
\hline \multicolumn{4}{|c|}{ Antidepressives } \\
\hline $\mathrm{T}_{1}(\mathrm{n})$ & 0 & 1 & \\
\hline$T_{2}(n)$ & 0 & 1 & \\
\hline \multicolumn{4}{|c|}{ Benzodiazepine } \\
\hline$T_{1}(n)$ & 3 & 6 & \\
\hline$T_{2}(n)$ & 6 & 4 & \\
\hline \multicolumn{4}{|l|}{ Biperiden } \\
\hline$T_{1}(n)$ & 0 & 5 & \\
\hline$T_{2}$ (n) & 6 & 5 & \\
\hline \multicolumn{4}{|l|}{$\mathrm{CPZ}$} \\
\hline $\mathrm{T}_{1}(\mathrm{M} / \mathrm{SD})$ & 0 & $1165 / 660$ & - \\
\hline $\mathrm{T}_{2}(\mathrm{M} / \mathrm{SD})$ & $519 / 227$ & $877 / 464$ & $1.96 /$ n.s. \\
\hline \multicolumn{4}{|l|}{ RSES } \\
\hline $\mathrm{T}_{1}(\mathrm{M} / \mathrm{SD})$ & 0 & $2.5 / 1.0$ & - \\
\hline$T_{2}(M / S D)$ & $3.8 / 2.6$ & $2.8 / 1.7$ & $0.79 /$ n.s. \\
\hline
\end{tabular}

(Overall and Gorham, 1962), and Scale for the Assessment of Negative Symptoms (SANS) (Andreasen, 1981).

Dosage calculations of chlorpromazine units were based on the procedure proposed by Davis (1974), while extrapyramidal side-effects were assessed using the Rating 
Scale for Extrapyramidal Symptoms (RSES: Parkinsonian syndrome, akathisia, dystonia) (DiMascio et al., 1976).

Significant improvements in clinical state from $T_{1}$ to $T_{2}$ were registered on all scales in both groups (cf. Table 1 for mean values and standard deviations; $t$-tests for dependent variables $(\mathrm{df}=7)$ :

a) group 1: GAS: $\mathrm{t}=-3.80 ; \mathrm{p}=.007$; BPRS: $\mathrm{t}=3.73 ; \mathrm{p}=.007$; SANS-SS: $\mathrm{t}=2.41 ; \mathrm{p}=.047$

b) group 2: GAS: $\mathrm{t}=-3.38 ; \mathrm{p}=.012$; BPRS: $\mathrm{t}=6.30 ; \mathrm{p}=.000$; SANS-SS: $\mathrm{t}=4.61 ; \mathrm{p}=.002$.

\section{Experimental procedure}

The experimenter conducted a semistandardized interview. The patient was asked questions about his/her general well-being, about the illness, and about how the individual was coping with his present situation. The interview lasted about ten minutes. After the initial questions, a period of $2.5 \mathrm{~min}$ was allowed for behavioral analysis. This was to ensure that the patients had already adjusted to the experimental setting. We limited the facial action assessment to $2.5 \mathrm{~min}$ because the analysis is very time-consuming and the time period is nevertheless a clinically relevant time segment.

\section{Automatic facial analysis}

With small round foil (diameter: $2.0 \mathrm{~mm}$ ) attached to different regions of the patient's face, we analyzed the range of facial action with the help of a computer program developed at our institute (Himer et al., 1991). The specially constructed scanning unit has a resolution of $1024 \times 2048$ pixels (horizontal $\times$ vertical), and scans 10 pictures per second. The yoked computer eliminates head movements and computes the $\mathrm{X}$ and $\mathrm{Y}$ coordinates for each facial action point with the help of four points of reference. The distance a point moves within the specified time is recorded and standardized (averaged across one second). The effect of the digital white noise on the computed point activity is $1.74 \mathrm{~mm} / \mathrm{sec}$.

In this study we assessed the mobility of 12 facial action points: Four facial action point foils were placed 1 $\mathrm{cm}$ above the inner/outer right and left eyebrow respectively, two $3 \mathrm{~cm}$ below the outer edges of the lower eyelid, two about $1 \mathrm{~cm}$ away from the nostrils, two close to the lip corners as well as about $1 \mathrm{~cm}$ above and below the midline of the mouth (Fig. 1). Since we took pictures of all of the patients with the attached facial action points at $T_{1}$, we were able to replicate the precise position of each point at $T_{2}$.

\section{Facial Action Coding System}

With the Facial Action Coding System (FACS) (Ekman and Friesen, 1978) facial expressions can be measured in a systematic manner. FACS is based on the functional anatomical structure of the facial musculature. It comprises 44 individual action units (AU), each representing a specific muscular facial action. At a speed of 25 video-frames/sec a temporal resolution of $40 \mathrm{msec}$ is possible. The coding of facial expressions with FACS is done in two separate steps, first coding the upper face and then the lower face. The coding was done independently by trained observers after passing the final



Fig. 1 Position of facial action points.

test for reliability. These observers also coded in real-time onoff patterns of vocalization during the interview.

\section{Statistical analysis}

The hypothesis of a reduction of facial action due to neuroleptics was analyzed with the help of unidirectional t-tests. Furthermore, we analyzed the data with global ANOVAs and bidirectional t-tests. Intragroup comparisons between $T_{1}$ and $T_{2}$ were performed using repeated-measure designs.

\section{Results}

\section{Global parameter of facial activity}

\section{Automatic analysis}

When averaged across 12 facial action points, a significant reduction of facial actions could be observed in group 1 (unmedicated at $T_{1}$ ) when $T_{1}$ and $T_{2}$ were compared $\left(\mathrm{T}_{1}: \mathrm{M}=2.52 \mathrm{~mm} / \mathrm{sec}, \mathrm{SD}=1.75 ; \mathrm{T}_{2}: \mathrm{M}=1.45, \mathrm{SD}=0.37\right.$; $t(7)=2.06 ; p=.037$; one-tailed). The facial actions in group 2 did not change significantly. The results were as follows: $1.70 \mathrm{~mm} / \mathrm{sec}(\mathrm{SD}=0.78)$ at $\mathrm{T}_{1}$ and $1.97(\mathrm{SD}=1.02)$ at $\mathrm{T}_{2}$ $(\mathrm{t}(7)=-0.99)$.

The significant effects of a $2 \times 2 \times 12$-ANOVA with the factors "Group" $(1,2)$, "Time" $\left(T_{1}, T_{2}\right)$ and "Facial Action Point Position" (1-12) using repeated measures confirmed these results: Group $\times$ Time $(F(1,14)=5.21 ; p=0.039)$, and Group $\times$ Time $\times$ Facial Action Point Position $(F(11,154)=$ $2.18 ; \mathrm{p}=.018$ ). Additionally, there was a significant main effect on Facial Action Point Position $(F(11,154)=24.39 ; p=.000)$, which was why we further analyzed the data separately for the upper and lower face.

\section{FACS}

A significant reduction of facial actions in group 1 could be observed during the course of the first three weeks $\left(T_{1}\right.$ to $\left.T_{2}\right)$. Also noticeable was a clear reduction in the 

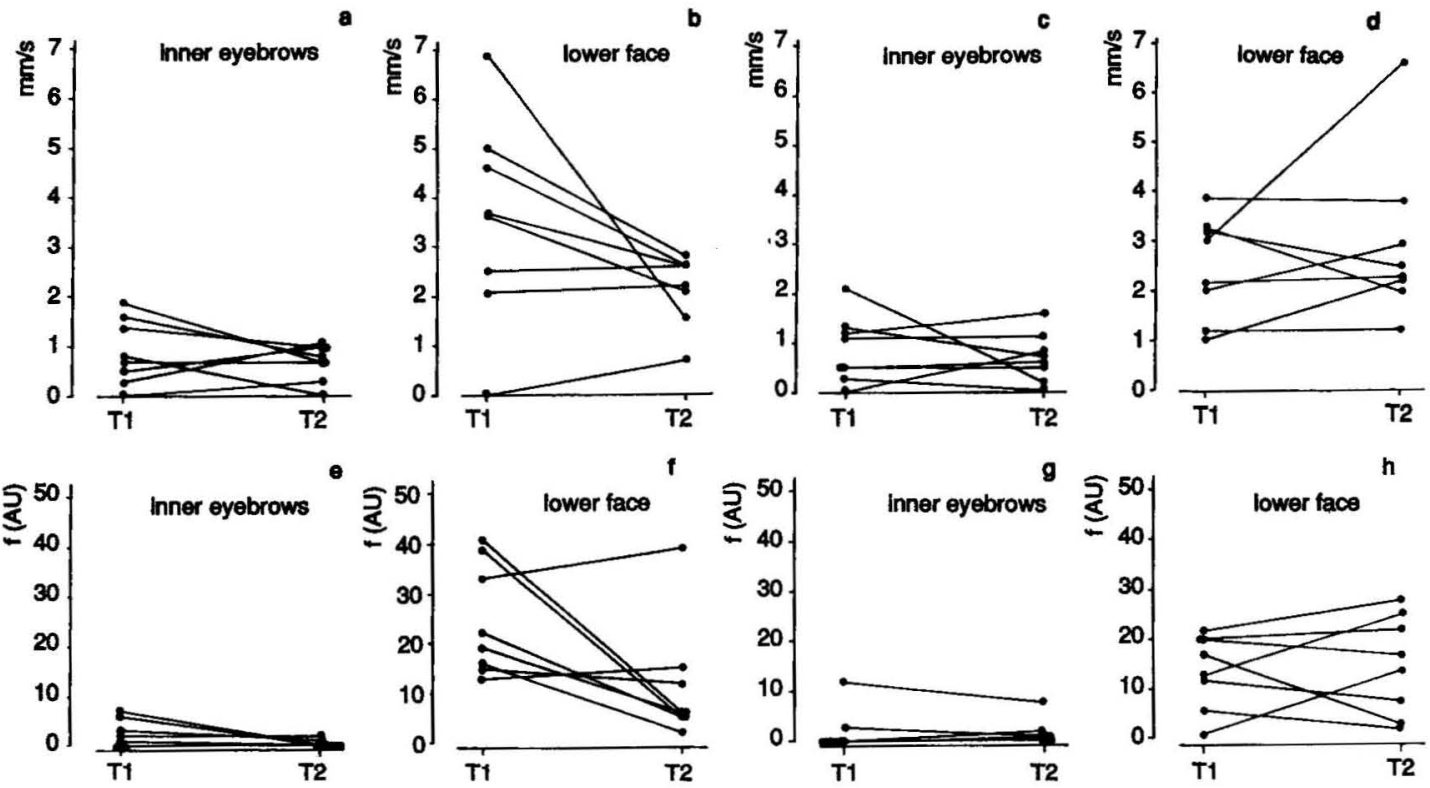

Fig. 2 Automatic analysis: a comparison of means $(\mathrm{mm} / \mathrm{sec})$ of both inner eyerbrow points with the means of six other facial action points of the lower face for 8 unmedicated patients (group 1; $\mathbf{a , b}$ ) and 8 medicated patients (group 2; c, d). The total number of AUs (FACS) in the lower
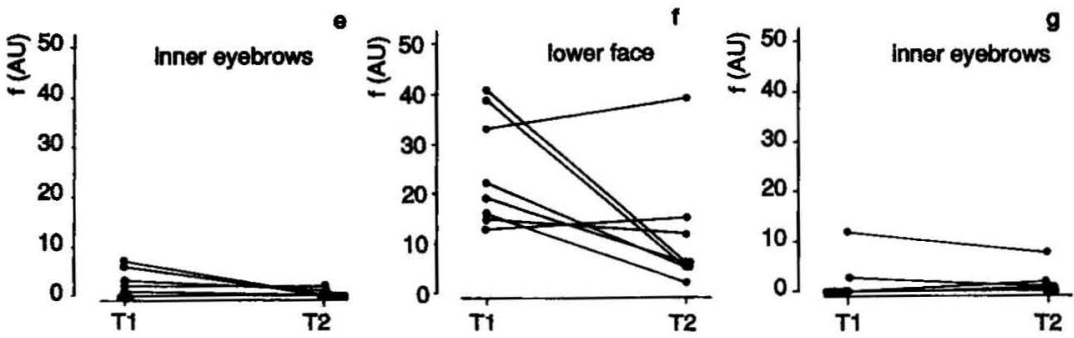
region of the upper face and the lower face of unmedicated (group $1 ; \mathbf{e , f}$ ) and medicated schizophrenic patients (group $2 ; \mathbf{g}, \mathbf{h}$ ) at $T_{1}$ and $T_{2}$ is also shown.

Tab. 3 Means (above) und standard deviations (below) of the activity (in $\mathrm{mm} / \mathrm{s}$ ) of the individual facial action points across group 1 and group 2 .

\begin{tabular}{|c|c|c|c|c|c|}
\hline \multicolumn{2}{|c|}{ Position } & \multicolumn{2}{|c|}{$\begin{array}{l}\text { Group } 1 \\
\text { (unmedicated) }\end{array}$} & \multicolumn{2}{|c|}{$\begin{array}{l}\text { Group } 2 \\
\text { (medicated) }\end{array}$} \\
\hline & & $\mathrm{T}_{1}$ & $\mathrm{~T}_{2}$ & & $\mathrm{~T}_{2}$ \\
\hline 1 & right cheek & $\begin{array}{l}1.99 \\
1.75\end{array}$ & $\begin{array}{l}0.92 \\
0.40\end{array}$ & $\begin{array}{l}1.07 \\
0.70\end{array}$ & $\begin{array}{l}1.67 \\
1.15\end{array}$ \\
\hline 2 & right outer brow & $\begin{array}{l}1.57 \\
2.07\end{array}$ & $\begin{array}{l}0.51 \\
0.58\end{array}$ & $\begin{array}{l}0.47 \\
0.50\end{array}$ & $\begin{array}{l}0.68 \\
0.99\end{array}$ \\
\hline 3 & left lip corner & $\begin{array}{l}3.12 \\
1.79\end{array}$ & $\begin{array}{l}1.99 \\
0.84\end{array}$ & $\begin{array}{l}2.11 \\
1.02\end{array}$ & $\begin{array}{l}2.92 \\
1.81\end{array}$ \\
\hline 4 & right nostril & $\begin{array}{l}1.42 \\
0.79\end{array}$ & $\begin{array}{l}1.15 \\
0.33\end{array}$ & $\begin{array}{l}1.12 \\
0.56\end{array}$ & $\begin{array}{l}1.60 \\
1.17\end{array}$ \\
\hline 5 & right inner brow & $\begin{array}{l}0.73 \\
0.73\end{array}$ & $\begin{array}{l}0.83 \\
0.41\end{array}$ & $\begin{array}{l}0.64 \\
1.10\end{array}$ & $\begin{array}{l}0.64 \\
0.94\end{array}$ \\
\hline 6 & upper lip & $\begin{array}{l}3.02 \\
2.75\end{array}$ & $\begin{array}{l}1.92 \\
1.64\end{array}$ & $\begin{array}{l}1.93 \\
1.16\end{array}$ & $\begin{array}{l}1.91 \\
1.91\end{array}$ \\
\hline 7 & lower lip & $\begin{array}{l}7.44 \\
5.87\end{array}$ & $\begin{array}{l}4.61 \\
3.76\end{array}$ & $\begin{array}{l}5.92 \\
2.93\end{array}$ & $\begin{array}{l}6.50 \\
3.51\end{array}$ \\
\hline 8 & left inner brow & $\begin{array}{l}0.91 \\
1.01\end{array}$ & $\begin{array}{l}0.55 \\
0.64\end{array}$ & $\begin{array}{l}0.93 \\
0.72\end{array}$ & $\begin{array}{l}0.74 \\
0.59\end{array}$ \\
\hline 9 & left nostril & $\begin{array}{l}1.72 \\
1.08\end{array}$ & $\begin{array}{l}0.92 \\
0.49\end{array}$ & $\begin{array}{l}1.48 \\
0.66\end{array}$ & $\begin{array}{l}1.61 \\
0.96\end{array}$ \\
\hline 10 & left lip corner & $\begin{array}{l}4.39 \\
3.00\end{array}$ & $\begin{array}{l}2.27 \\
0.86\end{array}$ & $\begin{array}{l}2.29 \\
1.18\end{array}$ & $\begin{array}{l}3.06 \\
1.96\end{array}$ \\
\hline 11 & left outer brow & $\begin{array}{l}1.17 \\
0.75\end{array}$ & $\begin{array}{l}0.52 \\
0.77\end{array}$ & $\begin{array}{l}0.65 \\
0.87\end{array}$ & $\begin{array}{l}0.53 \\
0.75\end{array}$ \\
\hline 12 & left cheek & $\begin{array}{l}2.82 \\
1.80\end{array}$ & $\begin{array}{l}1.17 \\
0.71\end{array}$ & $\begin{array}{l}1.72 \\
0.72\end{array}$ & $\begin{array}{l}1.73 \\
1.05\end{array}$ \\
\hline
\end{tabular}

total number of AUs in all patients $\left(\mathrm{T}_{1}: \mathrm{M}=34.75, \mathrm{SD}=13.0\right.$; $\mathrm{T}_{2}: \mathrm{M}=13.50, \mathrm{SD}=12.5 ; \mathrm{t}(7)=3.20 ; \mathrm{p}=.008$; one-tailed).

Furthermore, the nonmedicated patients showed a significant reduction in $\mathrm{AU}$ repertoire, i.e., the variability of facial expressions at $T_{2}$ in comparison to $T_{1}\left(T_{1}: M=\right.$ $\left.12.13, \mathrm{SD}=2.7 ; \mathrm{T}_{2}: \mathrm{M}=6.37, \mathrm{SD}=4.1 ; \mathrm{t}(7)=2.63 ; \mathrm{p}=.034\right)$. The average duration of the individual AUs (in sec) did not differ significantly at $\mathrm{T}_{1}$ or $\mathrm{T}_{2}\left(\mathrm{~T}_{1}: \mathrm{M}=1.88, \mathrm{SD}=0.6 ; \mathrm{T}_{2}: \mathrm{M}=\right.$ $2.59, \mathrm{SD}=1.1 ; \mathrm{t}(7)=-2.04 ; \mathrm{p}=.080)$.

No significant differences could be detected in group 2 when comparing these parameters at $T_{1}$ and $T_{2}$.

The group comparison at $T_{1}$ showed that the unmedicated patients (group 1) manifested more facial actions than group 2. The total number of AUs was somewhat higher in group 1 than in group 2 (group $1: \mathrm{M}=34.75, \mathrm{SD}=13.0$; group 2: $\mathrm{M}=19.75, \mathrm{SD}=12.0 ; \mathrm{t}(14)=2.39 ; \mathrm{p}=.016$; one-tailed). The difference became even more obvious in the number of different AUs displayed, i.e., in the facial action repertoire (group 1: $\mathrm{M}=12.13, \mathrm{SD}=2.7$; group 2: $\mathrm{M}=7.88, \mathrm{SD}=4.3$; $\mathrm{t}(14)=2.37 ; \mathrm{p}=.033$ ). No significant differences could be observed in the average duration (in sec) of a single AU (group 1: $\mathrm{M}=1.88, \mathrm{SD}=0.6$; group $2: \mathrm{M}=2.43, \mathrm{SD}=1.9 ; \mathrm{t}(14)=-0.69$; n.s.)

At $T_{2}$, there were no significant differences between the two groups with regard to these parameters.

\section{Upper face}

\section{Automatic analysis}

At $T_{1}$ and $T_{2}$, there was no difference in facial activity as measured by the facial action points at the inner eyebrows (points 5 and 8 ) of group $1(t(7)=0.44$; n. s.). 
Tab. 4 Means of the most important FACS Action Units for both groups at $T_{1}$ and $T_{2}$.

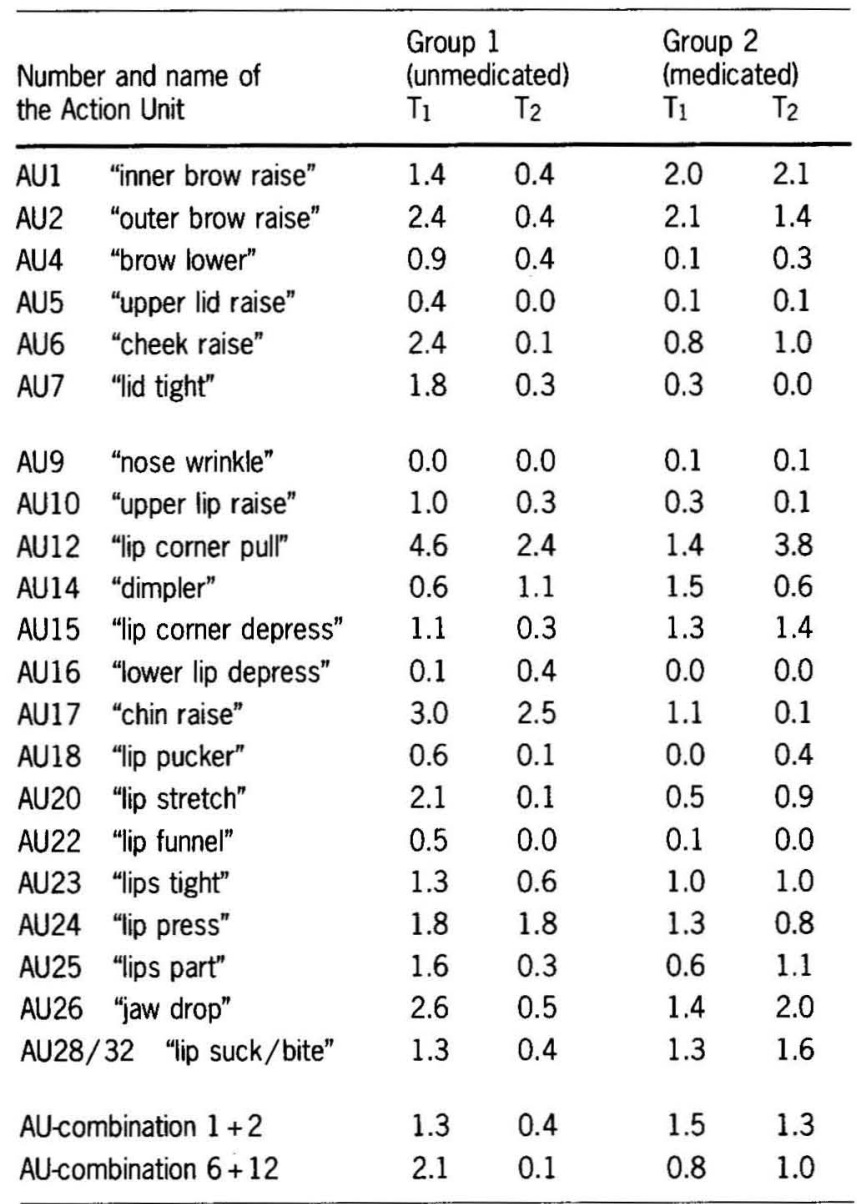

\section{FACS}

Between $T_{1}$ and $T_{2}$, there was a reduction in the total frequency of AUs 1 and 4 in group $1\left(\mathrm{~T}_{1}: \mathrm{M}=10.00, \mathrm{SD}=\right.$ $7.1 ; \mathrm{T}_{2}: \mathrm{M}=2.00, \mathrm{SD}=2.2 ; \mathrm{t}(7)=2.2 ; \mathrm{p}=.015$; one-tailed). The reduction in facial actions not only involved the concomitant upper facial activity when the patient was talking but also other AUs which can be regarded as indicator of emotional expressions (cf. Table 4).

\section{Lower face}

Automatic analysis

A comparison of $T_{1}$ and $T_{2}$ for the facial action points of the lower face (points $3,4,6,7,9$, and 10) showed a significant reduction in facial actions in group 1 at $T_{2}(t(7)=$ $2.01 ; p=.042$; one-tailed), and therefore reflect diminished activity of the lower face at $\mathrm{T}_{2}$.

\section{FACS}

Group 1 demonstrated a significant reduction in facial actions (AU9, 10, 12-15, 17, 18,20,22-28,30, and 32) in the time between $\mathrm{T}_{1}$ and $\mathrm{T}_{2}\left(\mathrm{~T}_{1}: \mathrm{M}=24.75, \mathrm{SD}=11.2 ; \mathrm{T}_{2}\right.$ : $\mathrm{M}=11.50, \mathrm{SD}=11.8 ; \mathrm{t}(7)=2.46 ; \mathrm{p}=.022$; one-tailed).
The reduction in individual AUs in the lower face is rather striking: the obvious reduction in AUs 12 and 20, as well as in AUs 10 and 15, indicate a reduced ability to express accompanying emotions. The reduction in AUs 25 and 26 indicates the concurrent reduction in general facial activity. AUs 14, 17, and 24, which belong to a group of AUs that represent accompanying emotional expressions, did not show any reduction at $T_{2}$.

\section{Verbal activity}

The findings presented are independent of the relative amount of vocalization during the interview (length of verbal activity in relation to duration of the interview). The relative verbal activity in group 1 was $38.5 \%$ at $\mathrm{T}_{1}(\mathrm{SD}=16.6)$ and $32.3 \%(\mathrm{SD}=14.2)$ at $\mathrm{T}_{2}(\mathrm{t}(7)=1.84 ; \mathrm{n} . \mathrm{s}$.$) , while in$ group 2 it was $36.6 . \%(\mathrm{SD}=14.1)$ at $\mathrm{T}_{1}$ and $34.6 \%(\mathrm{SD}=9.1)$ at $\mathrm{T}_{2}(\mathrm{t}(7)=0.34 ; \mathrm{n} . \mathrm{s}$.$) .$

\section{Discussion}

The patients in the two groups did not differ as to diagnoses, case history, psychopathology, age, or psychiatric inpatient treatment at $T_{1}$ and $T_{2}$. They did differ with regard to the onset of medication: group 1 was unmedicated at $T_{1}$ while group 2 was medicated. Moreover, six out of eight patients in group 1 had never been on any neuroleptics.

Computer-based facial action analysis allows the reduction of global facial activity in a typical clinical interaction to be attributed to the influence of neuroleptics (interaction: Group $\times$ Time with a three-factorial ANOVA). The variance in average facial activity in group 1 was significantly reduced at $T_{2}$ compared to $T_{1}$ (cf. Table 3 ): Inter-individual variability in group 1 was lower at $T_{2}$, and can therefore be attributed to the effects of neuroleptics.

Consequently, an objective assessment method is now available which can measure neuroleptically induced reductions in facial actions automatically. (In this respect, it might be of interest that See and coworkers were able to observe a reduction in oral activity in rats which had been on neuroleptics for a long time, although they used a different procedure (Ellison et al., 1987; Levy et al., 1987; See et al., 1988).)

As expected, no group differences with respect to facial actions could be observed at $T_{2}$ (about three weeks after $T_{1}$ ), as both groups were then receiving medication.

FACS produced almost the same results: it also showed a significant reduction in facial actions in group 1 between $T_{1}$ and $T_{2}$. Furthermore, the total number of facial actions was significantly reduced and a significant reduction in the variability of the facial action repertoire could also be observed.

When comparing both groups at $T_{1}$, group 1 differed significantly from group 2 with respect to the repertoire of facial actions. This difference in group 2 might have been caused by the neuroleptics they were taking, since neuroleptics are known to induce a reduction in facial expressivity in schizophrenic patients (cf. Schneider et al., 1990). 
Of further interest is the way in which facial actions are reduced under neuroleptics; i.e., the reduction in intensity of facial actions in group 1 between $T_{1}$ and $T_{2}$ was not the same for all facial action points. This effect was quite pronounced for the two facial action points attached below the inner eyebrow: no significant changes were observed. Both methods corroborated this result (cf. Fig. 2).

Both action points attached below the inner eyebrow, that means the underlying muscles, namely the corrugator muscle, could possibly play a specific role in the regulation of social interactions (cf. Ekman, 1979 and Grammer et al., 1988). Consequently, it may well be that reduced facial activity is confounded by improvement. This assumption could possibly be attributed to the fact that neuroleptics may have an effect on specific areas of the brain: the muscles of the upper facial region are functionally more closely connected to the formatio reticularis, the basal ganglia, and the "emotional" centers of the brain, whereas the muscles of the lower facial region are more under volitional control of the individual, since they are governed by the speech centers (Rinn, 1984).

When an improvement in well-being occurs, it is generally accompanied by an increase in verbal activity and, secondly, by more so-called illustrators, which are mostly expressed within the upper-middle facial region. The activity of the two facial action points attached above the inner eyebrow did not increase in group 1 from $T_{1}$ to $T_{2}$, but remained relatively constant (in comparison to the other facial action points, whose activity decreased significantly) (cf. Fig.2), while psychopathology also improved significantly. The relative stability of the facial activity of the two inner facial eyebrow points, assessed by automatic analysis, was verified by FACS, although the danger of a bottom effect is much more likely with FACS than with automatic analysis. On the other hand, possible artifacts in the automatic analysis can be detected by validation with the FACS scores.

If the previously introduced speculation would be correct, that the neuroleptically induced reduction in facial activity is confounded by an increase in facial activity during improvement, two opposing rendencies would exist. It remains an open question whether the reduction in facial activity induced by neuroleptics is a result of both motor and emotional sedation, which changes again during recovery.

With FACS, the individual AUs and their combinations can be assigned to specific emotions. A noticeable reduction in facial activity in group 1 was mostly expressed by AUs indicative of smiling. The most frequently recorded $\mathrm{AU}$ was $\mathrm{AU} 12$ and the AU-combination 6+12. The latter represents a "real" smile, and also involves the facial regions around the eye. This social smile in an interview situation is important in communication. The individual informs his partner that he/ she is in a friendly mood and thus reinforces that verbal activity of his partner positively.

Similarly, the AUs 20,10 and 15 were significantly reduced. AU 20 is a measure of fear. The AUs 10 und 15 represent the negative emotions disgust and sadness. A reduction of expressed fear corresponds well with the psychopathologic improvement observed between $T_{1}$ and $T_{2}$ during the course of therapy. No reduction took place in $\mathrm{AU} 17$, which represents embarrassment, or the AUs 14 and 24 (representing anger). The fact that the facial expressions of embarrassment and anger did not manifest a reduction, unlike other areas of facial activity, which were significantly reduced, is also indicative of improved psychopathologic symptomatology.

\section{Acknowledge}

Research was supported by a grant from the Deutsche Forschungsgemeinschaft. The authors would like to thank Ilse $M$. Zalaman for her assistance in the preparation of this manuscript.

\section{References}

Andreasen, N.: Scale for the Assessment of Negative Symptoms (SANS). The University of Iowa, Iowa City 1981

Bleuler, E.: Dementia praecox. Deuticke, Leipzig 1911

Davis, J. M.: Dose equivalence of the antipsychotic drugs. J. Psychiatric Res. 11 (1974) 65-69

DiMascio, A., D. L. Bernardo, D. J. Greenblatt, J. E. Marder: A controlled trial of amantadine in drug-induced extrapyramidal disorders. Arch. Gen. Psychiatry 33 (1976) 599-602

Ekman, P: About brows: Emotional and conversational signals. In: von Cranach, M., K. Foppa, W. Lepenies, D. Ploog (eds.): Human ethology. Claims and limits of a new discipline. Cambridge University Press, London (1979) 169-202

Ekman, P., W. Friesen: Facial Action Coding System: A technique for the measurement of facial movement. Consulting Psychologists Press, Palo Alto, CA 1978

Ellison, G., R. See, E. Levin, J. Kinney: Tremorous mouth movements in rats administered chronic neuroleptics. Psychopharmacol. 92 (1987) 122-126

Endicott, J., R. L. Spitzer, J. L. Fleiss, J. Cohen: The Global Assessment Scale. Arch. Gen. Psychiatry 33 (1976) 766-771

Esquirol, E.: Des Maladies Mentales. Considres sous les Rapports Médical, Hygiénique et Médico-Légal. Bailliére, Paris 1838

Grammer, K., W. Schiefenhövel, M. Schleidt, B. Lorenz, I. EiblEibesfeldt: Patterns on the face: The eyebrow flash in cross-cultural comparison. Ethology 77 (1988) 279-299

Heimann, H., T. Spoerri: Das Ausdruckssyndrom der mimischen Desintegrierung bei chronischen Schizophrenen. Schweiz. Med. Wochenschr. 35/36 (1957) 1126-1132

Himer, W., F. Schneider, G. Köst, H. Heimann: Computer-based analysis of facial action: A new approach. J. Psychophysiol. 5 (1991) 189 195

Kraepelin, E.: Lehrbuch der Psychiatrie. Abel, Leipzig 1883

Krause, R., E. Steimer, C. Sänger-Alt, G. Wagner: Facial expression of schizophrenic patients and their interaction partners. Psychiatry 52 (1989) $1-12$

Levy, A. D., R. E. See, E. D. Levin, G. D. Ellison: Neuroleptic-induced oral movements in rats: Methodological issues. Live Sci. 41 (1987) $1499-1506$

Marsden, C. D., D. Tarsy, R. J. Baldessarini: Spontaneous and drug-induced movement disorders in psychotic patients. In: Benson, D. F., D. Blumer (eds.): Psychiatric aspects of neurologic disease. Grune \& Stratton, New York (1975) 219-265

Martin, C. C., J. C. Borod, M. Alpert, A. Z. Brozgold, J. Welkowitz: Spontaneous expression of facial emotion in schizophrenic and right-brain-damaged patients. J. Commun. Disord. 23 (1990) 287 $-301$

Morison, A.: Physiognomik der Geisteskrankheiten. Ernst Schäfer, Leipzig 1853

Overall, J. E., D. R. Gorham: The Brief Psychiatric Rating Scale. Psychol. Rep. 10 (1962) 799-812

Owens, D. G. C., E. C. Johnson, D. C. Frith: Spontaneous involuntary disorders of movement. Arch. Gen. Psychiatry 39 (1982) 452-461

Pitman, R. K., B. Kolb, S. P. Orr, M. M. Singh: Ethological study of facial behavior in nonparanoid and paranoid schizophrenic patients. Am. J. Psychiatry 144 (1987) 99-102 
Rinn, W.: The neuropsychology of facial expression: A review of the neurological and psychological mechanisms for producing facial expressions. Psychol. Bull. 95 (1984) $52-77$

Rogers, D., N. Hymas: Sporadic facial stereotypies in patients with schizophrenia and compulsive disorders. Adv. Neurol. 49 (1988) 383-394

Sanberg, $P$. R.: Neuroleptic-induced emotional defecation: Effects of pimozide and apomorphine. Psychol. Behav. 46 (1989) 199-202

Schneider, F, H. Heimann, W. Himer, D. Huss, R. Mattes, B. Adam: Computer-based analysis of facial action in schizophrenic and depressed patients. Eur. Arch. Psychiatry Clin. Neurosci. 240 (1990) $67-76$

Schneider, F, R. Mattes, B. Adam, H. Heimann: Die Beurteilung des mimischen Ausdrucks schizophrener und depressiver Patienten durch Psychiater (Psychiatrists' ratings of facial expression of schizophrenic and depressive patients). Wien. Klin. Wochenschr. 104 (1992) 56-60

See, R. E., D. L. Edward, G. D. Ellison: Characteristics of oral movements in rats during and after chronic haloperidol and fluphenazine administration. Psychopharmacol. 94 (1988) 421 427

Steimer-Krquse, E., R. Krause, G. Wagner: Interaction regulations used by schizophrenic and psychosomatic patients. Studies on facial behavior in dyadic interactions. Psychiatry 53 (1990) 209-228

Wittchen, H. U., M. Zaudig, E. Schramm, P. Spengler, W. Mombour, J. Klug, R. Horn: Strukturiertes Klinisches Interview nach DSM-IIIR. Beltz, Weinheim 1987
Frank Schneider, M.D., Ph.D.

Department of Psychiatry

University of Pennsylvania

10th Floor, Gates Building

3400 Spruce Street

Philadelphia, PA 19104

USA 